\title{
El sur también existe. Las relaciones migratorias entre las islas Baleares y la Argelia francesa (1830-1962)
}

\author{
The South does also exist. Migratory Relationships between the \\ Balearic Islands and the French Algeria (1830-1962)
}

\author{
Antoni Marimon Riutort \\ Universitat de les Illes Balears
}

Recibido: 28-II-2013

Aceptado: 1-X-2013

\section{Resumen}

La Argelia francesa (1830-1962) constituyó un poderoso polo de atracción para los habitantes de las islas Baleares y del sudeste peninsular. En este artículo se analizan las relaciones migratorias y comerciales entre el archipiélago balear y su por entonces próspero vecino del sur. Además, también se estudian los diferentes exilios que vincularon las dos riberas del Mediterráneo. Para realizar este artículo se han combinado tanto fuentes primarias como la bibliografía existente.

Palabras clave: Emigración, Comercio, Contrabando, Colonización, Campesino, Exilio, Pied-noir, Frontera, Joan March.

\begin{abstract}
The French Algeria (1830-1962) constituted a powerful center of attraction towards the Balearic Islands and the peninsular Southeast's inhabitants. In this article we analyse the migratory and commercial relationships between the Balearic archipelago and its, in those days, wealthy neighbour from the South. Furthermore, we study the different exiles that linked the two Mediterranean shores. In order to make this article we combined both primary sources and the existing bibliography.

Keywords: Emigration, Trading, Smuggling, Colonization, Peasant, Exile, Pied-noir, Frontier, Joan March.
\end{abstract}




\section{Introducción}

En este estudio pretendemos ofrecer una primera visión global del proceso migratorio y de las relaciones económicas entre las islas Baleares y la Argelia francesa (1830-1962). Aunque ya existe una importante bibliografía que se ha ocupado de la emigración española a Argelia, ${ }^{1}$ con importantes estudios monográficos centrados en los casos de Alicante ${ }^{2}$, Valencia ${ }^{3}$ y Almería ${ }^{4}$, no disponíamos de ningún estudio global para el caso de las islas Baleares, si bien, como veremos, el caso concreto de la emigración de los menorquines a Argelia sí que ha generado una abundante producción historiográfica. Sin duda, la importante emigración hacia América Latina ${ }^{5}$ e incluso a Francia ${ }^{6}$ ha eclipsado las relaciones migratorias y los vínculos económicos entre las islas Baleares, sobre todo Mallorca e Ibiza, y el territorio argelino.

De hecho, incluso resulta difícil rastrear la memoria histórica de las otrora intensas relaciones con la Argelia francesa. Una colonia en la que la aportación migratoria hispánica siempre fue muy importante. En los inicios, en 1833, de 7.812 europeos civiles residentes en Argelia, unos 3.000 eran españoles, si bien

1. Son especialmente remarcables las obras de VILAR, Juan Bautista, Los españoles en la Argelia francesa, Murcia, Centro de Estudios Históricos-Consejo Superior de Investigaciones Científicas-Universidad de Murcia, 1989; VILAR Juan Bautista y VILAR, María José, La emigración española al Norte de África (1830-1999), Madrid, Arco Libros, 1999; y BONMATí ANTÓN, José F., Españoles en el Magreb, siglos XIX y XX, Madrid, Editorial Mapfre, 1992.

2. BONMATí, José F, La emigración alicantina a Argelia, Alicante, Publicaciones de la Universidad de Alicante, 1988; y viLAR Juan Bautista, "Los alicantinos en la Argelia francesa (1830-1914)", Anales de la Universidad de Alicante. Historia Contemporánea, no 1 (1983), pp. 127-161.

3. MENAgES, Àngela-Rosa y Monjo, Joan-Lluís, Els valencians d'Algèria, Picanya, Edicions del Bullent, 2007.

4. GÓMEZ díAZ, Donato, Las migraciones almerienses. Una historia económica hasta 1910, Almería, Instituto de Estudios Almerienses de la Diputación de Almería, 1995.

5. Algunas de las obras más importantes sobre la emigración balear a América Latina son las de BUADES CRESPí, Joan, MANRESA MONSERRAT, Mariantònia, y MAS BARCEló, Margalida A., El moviment associatiu balear a l'exterior. L'emigració de les Illes Balears a l'exterior, Binissalem, Govern de les Illes Balears. Conselleria de Presidència, 2001; BUADES CRESPí, Joan, MANRESA MONSERRAT, Mariantònia, MARIMON RIUTORT, Antoni, y MAS BARCELÓ, Margalida A., Emigrants illencs al Río de la Plata. La vida associativa a Buenos Aires i Montevideo, Palma, Vicepresidència del Govern Balear, 1995; BUADES CRESPí, Joan, 1889: l'allau emigratòria de mallorquins a l'Argentina i Xile, Binissalem, Govern de les Illes Balears, Conselleria de Presidència, 2002; y SERRA BUSQUETS, Sebastià, "Lemigració mallorquina a Amèrica Llatina de començaments de segle fins els anys 30 . El cas de l'Argentina", en Quinze anys dels premis d’investigació Ciutat de Palma, Palma, 1986, pp. 61-86.

6. vicens CASTANyer, Antoni, Sollerics a França. Passions i quimeres, Palma, El Tall Editor, 1993, y MARIMON RIUTORT, Antoni "L'emigració mallorquina a França fins al 1920", en BES HOGHTON, Isabelle (ed.), Illes Balears i França: traces i intercanvis, Binissalem, Casa Museu Llorenç Villalonga, 2008, pp. 31-51. 
las estadísticas francesas distinguían entre los españoles y los "mahoneses" (los emigrantes menorquines) que eran un millar y medio. Los emigrantes procedentes del sudeste peninsular muy pronto superaron ampliamente a los menorquines, pero en 1885-1886, Baleares todavía era la quinta provincia por el número de emigrantes a Argelia. En total, en 1882 había 114.320 emigrantes españoles en Argelia, sin contar a los clandestinos o a los que habían accedido a la nacionalidad francesa, mientras que el total de europeos ascendía a $412.435^{7}$.

Además, es preciso recordar que sólo el mar separa las costas de las islas Baleares del norte de África y que las distancias no son muy importantes. En concreto, Argel dista 315,1 km de Palma pero solo 287,4 km de ses Salines, en la parte más meridional de la isla de Mallorca. Ibiza, por su parte, se halla a 278,3 $\mathrm{km}$ de Argel, mientras que la pequeña isla de Formentera es el punto más próximo al norte de África, a 259,4 km de la capital de Argelia. La más septentrional de las islas Baleares, Menorca, se encuentra un poco más lejos. En el caso de Mahón, a 364,7 km, y en el de Ciudadela a 367,9 km al norte de Argel.

A continuación profundizaremos en las diversas fases en las que transcurrieron las relaciones migratorias entre las islas Baleares y la colonia francesa de Argelia y haremos referencia también a los vínculos económicos e incluso políticos que se fueron estableciendo.

\section{La emigración menorquina y las consecuencias del surgimiento de la colonia francesa de Argelia}

La conquista francesa de Argel en julio de 1830 fue seguida muy de cerca en las islas Baleares. De hecho los puertos de Mahón y Palma se convirtieron en la retaguardia de las tropas francesas que ocuparon Argel ${ }^{8}$. Muy pronto algunas personas de Mallorca y de Mahón se dirigieron a la capital norteafricana. Pero la emigración sólo adquirió un gran alcance en el caso de Menorca.

Aunque habían existido importantes relaciones comerciales antes de la ocupación francesa y la navegación balear dominaba el tráfico español con Argelia, la conquista de 1830 abrió la puerta a una emigración a gran escala y a la intensificación de todo tipo de contactos.

La causa inicial de la numerosa emigración menorquina fue el hambre y la miseria que provocaban las crisis de subsistencia originadas por una sucesión de malas cosechas en una isla con un comercio en decadencia a causa de una

7. VILAR Juan Bautista y VILAR, María José, La emigración española..., pp. 26-27.

8. VILAR Juan Bautista, "Las Baleares y la expedición francesa a Argel en 1830", Mayurqa, $n^{\circ} 13$ (1975), pp. 223-225. 
legislación estatal muy adversa y una industria casi inexistente ${ }^{9}$. Esta situación se conjugó con una política emigratoria francesa que en ocasiones facilitó la llegada de emigrantes, tanto españoles como de otras procedencias. En determinadas coyunturas, las autoridades de Argel llegaron a solicitar emigrantes, como en la primavera de 1832, cuando el cónsul francés en Palma tenía reunidas en esta ciudad a cincuenta familias de campesinos y pedía ayuda al vicecónsul en Ciudadela para completar la cifra de 200 familias de gente del campo solicitadas desde Argel ${ }^{10}$.

La corriente migratoria hacia esta colonia no siempre fue totalmente controlada por las autoridades, tanto francesas como españolas, que coincidían en permitir el traslado al norte de África únicamente de personas que tuviesen buena reputación y algunos medios de subsistencia. En el verano de 1832, el cónsul español en Argel estaba preocupado por la llegada de algunas mujeres menorquinas que protagonizaban conductas consideradas irregulares ya que algunas abandonaban a sus maridos para ir a vivir con italianos, franceses $u$ otros $^{11}$. Sin embargo, en 1834 las mujeres jóvenes de Menorca que quisieran trabajar como cocineras, lavanderas u obreras, podían conseguir sin problemas pasaporte para Argel, Orán, Bona o Bugia ${ }^{12}$. En el verano de 1835, la política favorable a la emigración del gobernador de Argel, el mariscal Clauzel, provocó un enorme incremento de la emigración española en general y menorquina en particular. En abril de 1836, un informe de un agente consular español hablaba de 1.900 nuevos emigrantes menorquines, de todas las edades y condiciones, incluidos religiosos, sacerdotes, niños y viejos ${ }^{13}$. Al final del año 1835 un particular, el barón de Vialar, organizó una red migratoria, que se prolongó durante dos años, entre Menorca y Argel. El objetivo de Vialar era impulsar la colonización agrícola con los "mahoneses", denominación con la que eran conocidos todos los menorquines en Argelia, ya que estaba convencido de su seriedad, capacidad y honradez. De Vialar instaló en sus tierras a familias enteras de menorquines y consiguió que otros terratenientes franceses también les dieran trabajo. Entre marzo y septiembre de 1836, según la prensa de Argel, más de 1.600 mahoneses habían llegado a Argelia. El mismo Vialar, en al-Haouch Kaid Ahmed, recreó un pueblecito menorquín con treinta

9. GOMILA, Jaume, "Lemigració menorquina a Algèria (1830-1850)", Revista de Menorca (Primer Trimestre, 1989), pp. 44-46.

10. GOMILA, Jaume y SASTRE, Josep, "Lemigració menorquina a Alger des del port de Ciutadella (1830-1850)", Revista de Menorca (cuarto trimestre, 1988), p. 491.

11. GOMiLA, Jaume, "L'emigració menorquina...", pp. 53-54.

12. Ibid., p. 59.

13. Ibid., p. 63. 
familias de "mahoneses"14. En 1841, las autoridades francesas solicitaban y facilitaban el embarque de mano de obra cualificada para trabajar en las obras de acondicionamiento de la llanura de Mitidja ${ }^{15}$. Todavía en 1845, la llegada de emigrantes menorquines a Argel era tan numerosa que el cónsul de España, alarmado, consideraba que Menorca, como Alicante, iba camino de quedarse desierta ${ }^{16}$.

En los años cincuenta, la política migratoria francesa fue cada vez más restrictiva. En 1858, se exige a los emigrantes que quieran pasar a Francia o a sus posesiones que tramitasen sus pasaportes en el consulado de Palma, de manera que se dificultaba enormemente la emigración de los menorquines ${ }^{17}$.

En conjunto, entre 1830 y 1836 salieron legalmente de Menorca 9.386 personas, que se dirigieron mayoritariamente a Argelia, aunque también hubo emigración hacia América ${ }^{18}$. Sólo por el puerto de Ciudadela, entre 1834 y 1850, partieron hacia Argel 4.324 personas, mayoritariamente de esta ciudad y de los municipios de la parte oriental de la isla. Se trataba de una emigración básicamente familiar, ya que nos encontramos ante un $44,4 \%$ de mujeres y un 55,6\% de hombres. Como es lógico los habitantes de Mahón y sus alrededores debían emigrar desde el puerto de Mahón, pero no hay datos al respecto $^{19}$. Es posible que la cifra total de los menorquines que se establecieron en Argelia en esos años pueda cuantificarse entre 12 y $15.000^{20}$, una cifra enorme para una isla de limitada extensión y población.

A causa de esta importante corriente migratoria, la población de la isla de Menorca experimentó una fuerte decadencia. La población total, que era de 37.559 habitantes en 1826, alcanzó un mínimo de 30.170 personas en $1844^{21}$, para irse recuperando lentamente en los años cincuenta y sesenta. Entre 1826 y 1857 se dio en Menorca un saldo migratorio negativo de nada menos que 9.418 personas $^{22}$.

14. JORDI, Jean Jacques, "La vida de los maoneses en Argelia. Un pueblo de colonización maonesa: Fort de l'Eau", Revista de Menorca (cuarto trimestre, 1990), p. 395.

15. GOMILA, Jaume y SASTRE, Josep, "L'emigració menorquina a Alger...", pp. 494-495.

16. GOMILA, Jaume, "L'emigració menorquina...", pp. 74.

17. GOMILA, Jaume y SASTRE, Josep, "Lemigració menorquina a Alger...", p. 491.

18. RIUDAVETS, Pedro, Historia de la isla de Menorca, Mahón, Imprenta de Bernardo Fábregues, 1885, vol. I, p. 492.

19. GOMILA, Jaume y SASTRE, Josep, "L'emigració menorquina a Alger...", pp. 500-502.

20. OLIVER FUSTER, Joan, "Un informe sobre la emigración de menorquines a tierras de Argelia en el siglo XIX", Trabajos de Geografía, no 35 (1978-1979), p. 134.

21. MARTí CAMPS, Ferran, Iniciació a la historia de Menorca, Palma, Editorial Moll, 1973, p. 173.

22. DUвON, Maria Lluïsa, "La emigración menorquina a Argelia en la primera mitad del siglo XIX. Detección y evaluación mediante demográfico directo e impacto sobre la evolución posterior a la población", en La geografía española y mundial en los años 
Los menorquines, emigraron inicialmente sobre todo a la capital, Argel, y a sus cercanías. Poco después se trasladaron hacia el este de la capital, con el apoyo de la administración militar y de algunos terratenientes y consiguieron concesiones de tierras. Las tierras del litoral, entre Mustapha y Reghaïa, unos 40 kilómetros, se convirtieron en huertos trabajados mayoritariamente por mahoneses. Las autoridades francesas consideraban que los "mahoneses" eran colonos excelentes y que eran imprescindibles para abastecer Argel de frutas y verduras. En esta región, en 1847, una cincuentena de familias menorquinas fundó un pueblo, Fort de l'Eau, que fue reconocido oficialmente por la República francesa en enero de 1850. La emigración menorquina se hizo permanente gracias a las concesiones de tierras, unas 300 al final de los años cincuenta ${ }^{23}$.

También pasaron a Argelia algunos mallorquines e ibicencos que desde 1845 afluyeron a la zona oriental costera de esta colonia, si bien también fueron llamados "mahoneses" por los franceses ${ }^{24}$. Entre 1878 y 1881, llegaron a Argelia algunos emigrantes mallorquines procedentes, como mínimo, de los municipios de Sóller y de Santanyí. En esos mismos años, persistía cierta emigración menorquina hacia Argelia en los municipios de Ciudadela, Mahón, Ferreries i es Mercadal. Las causas eran la falta de trabajo, el deseo de mejorar fortuna o la voluntad de escapar al servicio militar ${ }^{25}$.

Según las estadísticas oficiales francesas, en 1882 había 24.970 baleares en Argelia y un total de 99.700 españoles. Según el coetáneo historiador menorquín Pere Riudavets, dos tercios de los emigrantes baleares, o sea más de 16.000 colonos, procedían de la isla de Menorca ${ }^{26}$.

Algunos años más tarde, en febrero de 1888, un informe enviado por el vicecónsul español en Argel, Francesc Truyols, al archiduque Luis Salvador de Austria, ofrece unos datos algo diferentes, si bien ratifica la misma visión de conjunto. Así, residían en Argel unas 20.000 personas oriundas de Menorca, en su mayor parte hijos y nietos de los que emigraron en los años treinta y cuarenta. La emigración procedente de Mallorca era mucho más escasa, y podía cuantificarse en 1.000 o 1.200 personas. Los mallorquines, como los menorquines, se dedicaban principalmente a tareas agrícolas, arrendando tierras,

ochenta: Homenaje a D. Manuel de Terán, Madrid, Universidad Complutense, 1986. De esta misma autora, véase también "Les fluctuacions de la població menorquina a la primera meitat del segle XIX. Les emigracions a Algèria", en III Jornades d'Estudis Històrics Locals. La vida quotidiana dins la perspectiva històrica, Palma, Institut d'Estudis Baleàrics, 1985, pp. 49-59.

23. JORDI, Jean Jacques, "La vida de los maoneses...", pp. 399-401.

24. Ibid, p. 395.

25. Arxiu del Regne de Mallorca: Instituto Nacional de Estadística, Caja 260 (1881-1886). 26. RiUdaveTs, Pedro, Historia de la isla..., vol. II, p. 1.833. 
aunque residía en Argel un núcleo de comerciantes que se dedicaba principalmente al tráfico de caballos y otras bestias de carga.

Los menorquines habían fundado y habitaban en exclusiva dos pequeños pueblos, el citado Fort de l'Eau (actual Bordj El Kiffan), donde sólo el alcalde, los concejales y el maestro eran franceses, i Ain Taya, con casi mil habitantes menorquines, ambos a levante de la ciudad de Argel. También eran muy numerosos en otros pueblos de las cercanías de la capital, como Hussein Dey, con 1.200 menorquines, Comba (actual Kouba), con 900, Maison Carrée (actual El Harrach), con 700 y Rouïba, con otros 760. En El Biar, el único pueblo con abundante población menorquina situado al oeste de la capital, residían así mismo 1.160 isleños. Aunque no eran tan numerosos, también había contingentes importante de menorquines en Cap Matifou (actual Bordj El Bahri), con unas 300 personas de este origen, Reghaia, con 200 y Rivet con 240. En la capital y su comarca, se localizaban otros 3.000 menorquines.

Esta importante colonia se había mantenido agrupada y seguía escrupulosamente sus costumbres ancestrales. Además, mantenía con gran vigor el uso de su idioma, el dialecto menorquín de la lengua catalana ${ }^{27}$. En esos años la emigración se había restringido mucho por diversas causas, como la aplicación de una ley francesa de 1875 que sometía a quintas a la población de Argelia, la decisión del gobierno francés de otorgar sólo concesiones gratuitas de tierras a los ciudadanos galos y el desarrollo de la industria del calzado en Menorca ${ }^{28}$.

La persistencia del idioma materno de los menorquines también fue comprobado por el poeta catalán Jacint Verdaguer, que el año 1883 visitó Argel. Por cierto que según este testimonio también utilizaban un dialecto del idioma catalán los numerosos emigrantes que procedían de la provincia de Alicante ${ }^{29}$. En el seno de esta endogámica y, en general, respetable y trabajadora comunidad de emigrantes menorquines en Argelia, nació en 1882, en Birkhadem, Catalina Sintes Cardona, que en 1913 dio a luz al conocido escritor en lengua francesa Albert Camus. Catalina Sintes era hija de Catalina Maria Cardona Fedelich, nacida en Sant Lluís (Menorca) y de Esteve Sintes Cursach, que ya había nacido en Argel hijo de padres menorquines emigrados a Argelia antes de $1850^{30}$.

27. OLIVER FUSTER, Joan, "Un informe sobre...", pp. 134-135.

28. Sobre el desarrollo de la industria del calzado en Menorca, veáse MARQUÈs SINTES, Miquel A., Industrials i artesans de Menorca. El cas d'Alaior (1852-1936), Palma, El Tall, 1993 y CASANOVAS, Miquel-Àngel, L'economia menorquina en el segle XIX (1802-1914), Palma, Edicions Documenta Balear, 1998.

29. marfany, Marta, Els menorquins d'Algèria, Barcelona, Publicacions de l'Abadia de Montserrat/ Institut Menorquí d'Estudis, 2002, p. 33.

30. PONS FRAGA, Josep, "Entre Menorca i Algèria", El Mirall, no 93 (mayo 1998), pp. 6-8. 
La ocupación francesa de Argelia también permitió incrementar el comercio con España en general y con las islas Baleares en particular. En 1833, España ocupaba el segundo lugar en el comercio exterior argelino y tres cuartas partes de los barcos que visitaron los puertos de la colonia francesa tenían su base en las Islas Baleares. En estos intercambios comerciales jugaba un papel muy importante el puerto de Mahón, pero tampoco pueden menospreciarse los puertos de Palma e Ibiza. En general, desde Mahón, Ciudadela y Palma se comerciaba con Argel y con los puertos de la costa central y oriental de Argelia, mientras que desde Ibiza eran más frecuentes los contactos con la relativamente cercana Orán ${ }^{31}$. En los años cuarenta del siglo XIX, por el puerto de Ciudadela se exportaban materiales de construcción, ganado, patatas, legumbres y fruta, así como queso, pescado y marisco, vino, aceite, aguardiente y también escobas y sombreros $^{32}$. Ya en los años sesenta y setenta del siglo XIX, Mallorca exportaba, entre otros productos, corteza de encinas y ganado, Menorca pequeñas embarcaciones, marisco, sillares de piedra y escobas, e Ibiza, madera y algarrobas ${ }^{33}$.

La colonización de Argelia por Francia también supuso la aparición de un vasto y próspero territorio de corte occidental pero de soberanía política diferente a la española. Esta especie de nueva y permeable frontera meridional pronto fue aprovechada por algunos isleños con problemas políticos o de delincuencia común con las autoridades españolas. Pero también se podía seguir, como veremos, el camino inverso y por los mismos motivos. Ya en septiembre de 1835, algunos "mahoneses" implicados en una intentona revolucionaria que quería seguir el ejemplo de Barcelona, prefirieron antes huir a Argelia que hacer frente a la represión gubernamental ${ }^{34}$. En los años sesenta del siglo XIX, en la isla de Ibiza, a diferencia de Mallorca y Menorca, eran relativamente frecuentes los asesinatos por arma blanca a causa de peleas entre jóvenes. Los homicidas, para llegar a la justicia española, intentaban escapar a África, dirigiéndose frecuentemente a la Argelia francesa ${ }^{35}$.

Pero también se dio el caso de prófugos de la justicia francesa que desde Argelia consiguieron llegar a las costas mallorquinas. Este fue el destino de un grupo de deportados políticos contrarios al régimen de Napoleón III. Se

31. VILAR, Juan Bautista y DUBOn, M. Lluïsa, "Algunes notícies entorn dels riscs de la presència balear a les mars d'Algèria al començament de la fase colonial. Naufragis, acció del cors musulmà i exaccions franceses al 1833", Randa, nº 20 (1986), pp. 48-54.

32. GOMILA, Jaume y SASTRE, Josep, "L'emigració menorquina a Alger...", pp. 513-515.

33. D’ÀUSTRIA, Arxiduc Lluís Salvador, Les Balears descrites per la paraula i la imatge, Palma, Promomallorca Edicions, 1999-2003, vol. I, p. 102, vol. III, pp. 372, 466, 467 y vol. VI, pp. 493, 510, 517, 518, 563, 565.

34. JORDI, Jean Jacques, "La vida de los maoneses...", p. 392.

35. D’ÀuStriA, Arxiduc Lluís Salvador, Les Balears descrites... vol. I, p. 29. 
trataba de Émile Digeon (1822-1894), del joven abogado Houillier y del padre del primero. Este grupo de abogados izquierdistas consiguió llegar a Mallorca en un destartalado barco de contrabandistas, probablemente del populoso barrio marinero de Santa Catalina (Palma). Émile Digeon se instaló en Palma y contrajo matrimonio, hacia 1853, con una rica viuda francesa residente en Mallorca desde hacía más de dos décadas, Hélène Choussat ${ }^{36}$.

Por otra parte, Argelia se convirtió muy pronto en un refugio para aquellos jóvenes que no querían hacer el servicio militar. El rechazo a las quintas era especialmente agudo en Menorca, una isla que durante mucho tiempo había estado exenta. Ya en 1838, diversos informes de los ayuntamientos de Menorca coincidían en afirmar que los jóvenes pasaban a África para evadirse del sorteo de las quintas ${ }^{37}$.

\section{La emigración balear a finales del siglo XIX y en el primer tercio del siglo XX}

En general, la emigración española a Argelia tendió a disminuir notablemente en los años ochenta. Las provincias que, en el bienio 1885-86, aportaron más emigrantes fueron Almería, Alicante, Murcia, Valencia y Baleares. Además, excepto en el caso de Almería, el número de repatriados compensaba la emigración. Predominaban claramente los agricultores y seguían a continuación los comerciantes, siendo escasos los profesionales liberales. Esta emigración tenía un carácter temporal y era motivada, en general, por los problemas climáticos de las regiones del sudeste peninsular con épocas de sequía que contrastan con graves inundaciones, y por los mayores jornales que se pagaban en Argelia a los trabajadores del campo así como por la rapidez y baratura del viaje ${ }^{38}$.

Sin embargo, al menos en el caso de las Islas Baleares, la crisis agraria de 1889 , los estragos provocados por la filoxera a partir de 1891 y los problemas económicos causados por la crisis colonial de 1895-1898, favorecieron un repunte de la emigración a Argelia. Así, según la Estadística de Emigración e Inmigración en España, 1891-1895, el principal destino de la emigración de las Islas Baleares fue precisamente Argelia, hacia donde pasaron 2.034 personas (el $35,4 \%)$, y a continuación encontramos Cuba, Puerto Rico y la Argentina ${ }^{39}$.

36. Choussat, Hélène, Memòries. 1810-1896, Palma, Ajuntament de Palma/ Institut d'Estudis Baleàrics/ Quetglas Tous SL, 2010, pp. 212-214; y TiRand, Paul, Émile Digeon 1822-1894. Litinéraire singulier d’un communard, Paris, L'Harmattan, 2006.

37. GOMILA, Jaume, "Lemigració menorquina...", pp. 44-45.

38. FUENSANTA DE PALMA, Marqués de la, El problema migratorio, Madrid, Imprenta del Asilo de Huérfanos del S.c. de Jesús, 1905, pp. 137-138.

39. BARCEló PONS, Bartomeu, "L'emigració a les Illes Balears", Lluc, no 750 (1989), pp. 3-6. 
Afortunadamente, disponemos de otras fuentes ${ }^{40}$ que nos aportan datos muy concretos sobre la emigración entre los años 1892 y 1900. En este período pasaron a Argelia desde las islas Baleares 4.828 personas, si bien desde la colonia francesa llegaron a las Baleares 4.478 hombres y mujeres con un saldo final negativo de sólo 290 personas, de manera que no hay duda sobre el carácter muy mayoritariamente temporal de esta emigración. Con todo, se trataba del flujo migratorio directo más importante, seguido del que se dirigía a la Francia metropolitana.

Por islas, 1.763 menorquines pasaron a Argelia en esos años, siendo la colonia francesa, con mucha diferencia, el principal destino de la emigración de Menorca. Curiosamente, eran más los emigrantes que partían del puerto de Ciudadela que los que lo hacían por el de Mahón. En conjunto, la emigración menorquina se incrementó mucho en los años 1895-1898, para decaer a continuación. En el caso de Ibiza, el predominio de la emigración a Argel también era abrumador, con un total de 1.396 personas y con su punto más álgido en los años 1895 y 1896. En cuanto a Mallorca, la emigración a Argelia, 1.669 personas, sólo era superada por la que se dirigía a Francia. Casi todos los emigrantes partían del puerto de Palma y los años de mayor emigración fueron 1898 y 1900, con 285 y 386 personas respectivamente.

En general, los meses de más afluencia de emigrantes eran los de la primavera y el verano, hasta octubre. Sin embargo, en algunos años, la emigración empieza en marzo, como en el puerto de Palma en 1897, o incluso en febrero, como fue el caso del año 1898 en la capital insular. Otra curiosa excepción es la de Ciudadela, con cierta emigración ya en enero de 1897 y en ese mismo mes de 1898. Con todo, es significativo que en un puerto de escasa emigración a Argelia, el de Mahón, en 1894 sólo hay emigración entre junio y septiembre, y al año siguiente, en 1895, entre julio y octubre.

No hay duda que este ciclo migratorio está vinculado con la producción agraria argelina, que, por cierto, era más temprana que en la ribera norte del Mediterráneo. En consecuencia, la emigración de los meses de primavera está relacionada con la cosecha de cereales, mientras que la de los meses de verano y de otoño se vincula a la vendimia y a las cosechas de algodón, arroz, maíz y oliva. En cuanto a la inmigración, en el puerto de Palma los meses más intensos son los de julio y agosto, aunque en algunos años, como 1895, los retornos también son muy numerosos en mayo, junio y septiembre. Es muy

40. Nos referimos a las "Estadísticas de emigraciones e inmigraciones" de la Dirección General del Instituto Geográfico y Estadístico publicadas en la Gaceta de Madrid entre 1892 y 1901. Las hemos podido consultar en la Biblioteca del Parlament de les Illes Balears. 
probable que este retorno se vincule a la cosecha de cereales y de almendras en Mallorca. En el caso de Ibiza, es difícil establecer una pauta, ya que hay años, como en 1894, en que los retornos se escalonan desde febrero a diciembre con la única excepción del mes de octubre. En cambio, en 1892, los retornos se concentran entre mayo y diciembre, mientras que en 1898, lo hacen entre febrero y septiembre.

Por lo que se refiere al puerto de Ciudadela, inicialmente los retornos se producen en junio, julio y octubre (1892) o en mayo, junio, septiembre y octubre (1893). Pero en 1896, 1897 y 1898, se concentran en los meses de mayo a septiembre. Curiosamente, en 1898 no hay retornos en el mes de agosto, pero son numerosos en abril, mayo y junio así como en septiembre, noviembre y diciembre. Al año siguiente, no hay un solo viajero que llegue de Argel en los meses de junio, julio y agosto. Este comportamiento puede explicarse por la singular estructura agraria de Menorca, una isla con poca o nula producción de cereales y de almendras.

La diversidad insular también se hacía notar en la proporción de mujeres que emigraban. Así, mientras en Mallorca e Ibiza la proporción de mujeres emigrantes era exactamente la misma, el 28,3\%, en Menorca el porcentaje de féminas emigrantes, siempre en el período 1892-1900, fue del 40,4\%. Por otra parte, también resulta interesante constatar que, para el total de la emigración a Argelia, el balance entre emigrantes e inmigrantes era ligeramente positivo en Mallorca (30 personas), mientras que arrojaba un balance negativo en Menorca (118 personas) e Ibiza (202 personas).

En la primera década del siglo XX, en concreto entre 1901 y 1909, según las estadísticas del Movimiento de Buques y Pasajeros ${ }^{41}$, continúan siendo muy importantes las relaciones migratorias entre las islas Baleares y Argelia. De hecho, se produce un notable incremento a partir de 1904, con 616 salidas y 1.394 entradas sólo en ese año. Por cierto, que en todo este período el saldo migratorio es siempre positivo, con cifras máximas de 831 personas en 1909 y un mínimo de 44 en 1902. Predominan claramente los agricultores y las personas sin trabajo aunque no son menospreciables los porcentajes de trabajadores industriales y comerciantes.

En los años veinte, inicialmente las relaciones migratorias siguen siendo importantes, con 828 salidas y 1.322 llegadas en 1921, pero la tendencia es hacia una cierta disminución. Con todo, en el último año del que disponemos de información completa de las salidas hacia Argel así como de las entradas pro-

41. ANDREU VIVES, Joan y BORRÀS REYENÉS, Joan, "Les Balears i Algèria : anàlisi d'un fet migratori", Lluc, no 827 (2002), pp. 18-27. 
cedentes de esta colonia, que es 1928, todavía suman 581 y 459 personas, respectivamente. Por cierto que, a partir de 1923 y excepto en 1927, las salidas superan a las entradas, de manera que el saldo migratorio es negativo. En cuanto a los oficios y profesiones de los emigrantes, en los años veinte predominan los que figuran sin trabajo, aunque seguramente resulta más significativo el lento crecimiento de los trabajadores industriales y de los comerciantes ${ }^{42}$.

También disponemos de datos concretos sobre la emigración en algunos municipios de Mallorca. En el caso del municipio de Manacor, uno de los más importantes de la isla, situado a levante, el censo de 1887 aporta 53 personas residiendo en Argelia, aunque nueve de ellos habían nacido en el vecino municipio de Felanitx. Habían emigrado tanto familias enteras de jornaleros y de labradores como algunos jornaleros en solitario. Casi la mitad de los emigrantes, 24 personas, eran de sexo femenino, entre mujeres casadas, solteras, niñas e incluso una viuda. Significativamente, todos estos campesinos, excepto un labrador, eran totalmente analfabetos ${ }^{43}$. Posteriormente, la emigración a Argel parece haber perdido parte de su importancia. Entre 1894 y 1911, están documentados únicamente nueve emigrantes, todos varones y jornaleros o labradores $^{44}$.

En cambio, en el pequeño municipio de Lloseta, en la comarca del Raiguer, si bien se documenta un caso de un jornalero que ha emigrado a Argel, la mayoría de emigrantes eran zapateros. Pero esta emigración era muy limitada, ya que entre 1908 y 1920 sólo se localizaron seis llosetenses en Argel, a los que se podrían añadir dos niños nacidos en la capital africana pero residentes en Lloseta, una prueba más del ir y venir entre Argelia y las islas Baleares ${ }^{45}$.

Un caso muy diferente es el de Sóller, una pequeña ciudad ubicada en un valle de la costa norte de Mallorca. Hemos podido documentar que desde su pequeño puerto partieron directamente hacia Argel 11 personas ( 9 hombres y 2 mujeres) en febrero de 1896 y se registraron once entradas procedentes de la capital africana, en concreto 3 hombres y 8 mujeres, el mes de enero de 1897. Algún tiempo después, en mayo de 1900, desembarcaron en el Puerto de Sóller procedentes de Argel nada menos que 94 hombres y 15 mujeres ${ }^{46}$. De todas maneras, la emigración desde Sóller había comenzado mucho antes. En 1841

42. Ibid., pp. 22-24.

43. Arxiu Muncipal de Manacor, caja 1.397, Censo de 1887.

44. Arxiu Municipal de Manacor, cajas 1.088 y 1.089 (padrón municipal de 1905); 1.098 y 1.099 (padrón municipal de 1909); 1.102 y 1.103 (Censo de 1911).

45. BIBILONI AMENGUAL, Andreu, La construcció d'un poble. Lloseta i les migracions durant el segle XX, Palma, Edicions Cort, 2005, pp. 128-131.

46. "Estadísticas de Emigraciones e Inmigraciones", Gaceta de Madrid, 1896, 1897 y 1900. 
ya residía en Argel un emigrante procedente de Sóller, y hasta 1870, como mínimo otros seis sollerenses se desplazaron a Argelia. Precisamente era natural de este municipio Salvador Coll Terrassa (1802-1884) un emigrante excepcional que hizo fortuna en Cuba y Méjico si bien después pasó a Francia para recalar a continuación en Argelia, concretamente en la región occidental de Annaba. Adquirió una gran finca rústica desde la que exportaba frutos secos principalmente hacia la Francia metropolitana. En 1860, era considerado el único emigrante notable por su riqueza procedente de España ${ }^{47}$.

La verdad es que la mayoría de los emigrantes sollerenses, a diferencia de los españoles e incluso del resto de baleares, se dedicaban principalmente al comercio de frutas y verduras. Era bastante frecuente que primero hubiesen emigrado a la Francia metropolitana y posteriormente se instalasen en Argel. Ya en los años treinta del siglo XX, conocemos algunas empresas importantes como F. Mayol et Frères ${ }^{48}$ o C. Colom et ses Gendres. Esta última se trasladó a Argel desde Saint-Étienne hacia 1931 y consiguió una notable expansión. Exportaba frutas y verduras de Argelia así como de la Península Ibérica y de Marruecos hacia los mercados franceses. Para ello disponía de una red de agentes comerciales, formada principalmente por mallorquines, aunque también contaba con algunos franceses, que se extendía por toda Francia. Curiosamente, esta empresa se benefició de la coyuntura bélica de la Segunda Guerra Mundial, ya que los problemas alimentarios de la Francia metropolitana incrementaron fuertemente la demanda de fruta y verdura de Argelia ${ }^{49}$.

\section{Los vínculos económicos. El comercio legal y el contrabando. El papel de Joan March}

La intensificación de las relaciones de todo tipo entre Mallorca y Argelia fue facilitada por la mejoría de las comunicaciones. A finales del siglo XIX, los viajes entre Palma y Argel todavía tenían un carácter eventual ${ }^{50}$. Pero en 1910, la Isleña Marítima, la principal naviera mallorquina, se hizo cargo de una comunicación regular con Marsella y Argel. En 1930, partía un barco de Palma hacia Argel día 23 de cada mes y de Argel hacia Palma el 25 de cada mes ${ }^{51}$. Justo

47. VILAR, Juan Bautista y VILAR, María José, La emigración española..., p. 40.

48. QUETGLAS CIFRE, Antoni y ESTADES ENSEÑAT, Joan, L'emigració sollerica (1836-1936), Palma, Govern de les Illes Balears/ Ferrocarril de Sóller/ Fundació Tren de l'Art, 2009, p. 102.

49. MARIMON RIUTORT, Antoni, D'Alger a sa Granja d'Esporles passant per Amèrica. Semblança biogrăfica de Cristòfol Seguí Colom, Palma, Edicions Documenta Balear, 2011, pp. 21-33.

50. PUJALTE, Ferran, Transports i comunicacions a les Balears durant el segle XIX (1800-1890), Palma, Edicions Documenta Balear, 1999, pp. 40 y 60.

51. Calendario de La Almudaina, Palma, Amengual y Muntaner, 1930, p. 8. 
antes de la Guerra Civil, las relaciones entre estos dos puertos se había intensificado considerablemente. Entre agosto de 1935 y julio de 1936 llegaron a Palma 53 barcos procedentes de Argel, que representaban el 14,7\% de todos los navíos arribados a la capital insular. La inmensa mayoría pertenecían a la Compagnie de Navegation Mixte, que cubría la línea Marsella-Palma-Argel. Sus barcos eran mixtos de carga y pasaje y desembarcaron, en ese mismo período, 1.339 pasajeros, que suponían el 23\% de todos los viajeros que llegaron a Palma $^{52}$. Por otra parte, sobre todo en los primeros años del siglo XX, se organizaron viajes puntuales de carácter turístico que trasladaron a Argel a decenas de baleares. Este fue el caso del vapor <El Balear>, que transportó 91 excursionistas desde Ibiza a Argel, entre el 14 y el 20 de mayo de 1912. En esa época un viaje así se convertía en un evento social y político ya que los viajeros fueron recibidos por las autoridades francesas de Argelia y por el vicecónsul español en Argel. Además, cabe señalar que la expedición ibicenca era la respuesta a la que había llegado a Ibiza procedente de Argel en agosto de $1911^{53}$.

En cuanto a las mercancías, entre 1926 y 1936, la Argelia francesa fue el principal destinatario fuera de España de productos industriales alimenticios exportados por el puerto de Palma. También eran importantes las exportaciones de calzado, alimentos varios, almendras, pulpa de frutas y conservas. En esos mismos años se importaban por el puerto de Palma procedentes de Argelia grandes cantidades de fibras vegetales, productos químicos y mercancías llamadas "coloniales". Además, se importaban alimentos, materiales de construcción y cueros ${ }^{54}$. En los años treinta, por otra parte, algunos arrendatarios (amos) mallorquines continuaban comprando asnos y caballos en Argel, principalmente para las tareas del campo pero también para competir en los hipódromos de la isla ${ }^{55}$. Aunque, evidentemente, las comunicaciones marítimas siempre fueron las más importantes, no podemos dejar de mencionar que ya en 1923, la compañía francesa Latécoère estableció una línea de hidroaviones entre Tolouse, Palma y Argel, si bien parece que sólo hacían una escala técnica en Mallorca ${ }^{56}$.

52. mulet Gomila, Antoni, "Importancia del turismo en Mallorca", Boletín de la Cámara Oficial de Comercio, Industria y Navegación de Palma de Mallorca, $\mathrm{n}^{\circ} 563$ (junio-agosto 1945), pp. 49-64.

53. FajARnES RAMON, Enrique A., De Ibiza a Argel. (Impresiones de un viaje), Palma, Imprenta de las Hijas de F. Colomar, 1912.

54. MANERA, Carles, Història del creixement econòmic a Mallorca (1700-2000), Palma, Lleonard Muntaner, Editor, 2001.

55. Entrevista a Francisco Frau Palmer (Can Valero, Palma, 1923), Son Sardina (Palma), $15-\mathrm{XII}-2012$.

56. Rosselló verger, Vicenç M., Prehistòria de l'aviació a Mallorca, Palma, Obra Cultural Balear, 1974, pp. 20-21. 
Posteriormente, en 1934, la compañía francesa de aviación Air France inauguró una línea de hidroaviones entre Marsella, el puerto de Alcúdia (Mallorca) y Argel ${ }^{57}$.

Pero Argelia también fue, hasta la Guerra Civil de 1936, el principal foco de comercio ilegal hacia Baleares, especialmente del contrabando de tabaco. Ya en los años treinta del siglo XIX, se estimaba que los españoles, y principalmente los menorquines, representaban una cuarta parte del comercio clandestino en Argelia ${ }^{58}$. En 1840, el cónsul francés en las islas Baleares, Hersant, se quejaba que los capitanes de los barcos de estas islas hacían escala en otros puertos antes de llegar al norte de África, favoreciendo de esta manera el contrabando ${ }^{59}$. Además, el contrabando no estaba socialmente mal considerado, de manera que era una actividad que contaba con múltiples complicidades en las islas Baleares. Sólo en el período 1861-1865, fueron procesadas por contrabando 283 personas ${ }^{60}$. El principal producto objeto del comercio ilegal era el tabaco, hasta el punto que este era el destino de la mayor parte de la producción de las fábricas de elaboración de tabaco que se crearon en Argel y Orán. Ya en la época de la Restauración, un mallorquín, Josep Garau, natural del pueblo de Santa Margalida, era propietario de una de estas fábricas en Argel y uno de los principales proveedores de tabaco para los contrabandistas mallorquines. Pero en 1904, hizo su aparición en Argelia un potente competidor. Se trataba de un joven emprendedor, del mismo pueblo que Garau, Joan March Ordinas conocido como En Verga. En ese año, este ambicioso comerciante mallorquín adquirió la fábrica de tabacos que poseía en Orán Vicent Jorró, miembro de una familia alicantina de ideología carlista que se había trasladado a la Argelia francesa para evitar represalias políticas. Durante algunos años, Garau y March lucharon para dominar el mercado del contrabando de tabaco, sin embargo, Josep Garau comprendió que le convenía más asociarse a Joan March que continuar una pugna de dudosa final. En 1909, Joan March pasó a ser copropietario de la fábrica de Garau ${ }^{61}$. Por otra parte, desde 1902 el joven Joan March era socio de otro comerciante mallorquín, natural de Alcúdia, Antoni Ques Ventayol, que se inició en el contrabando de tabaco en ese mismo año cuando el Gobierno civil de Alicante autorizó su

57. PUjalte, Ferran, Transports i comunicacions a les Balears durant el segle XX, Palma, Edicions Documenta Balear, 2002, p. 35.

58. GOMILA, Jaume, "Lemigració menorquina...", pp. 71.

59. JORDI, Jean Jacques, "La vida de los maoneses...", pp. 389

60. D’ÀUSTRIA, Arxiduc Lluís Salvador, Les Baleares descrites...”, vol. II, p. 204.

61. FERRER GUASP, Pere, Joan March. Els inicis d'un imperi financer, Palma, Edicions Cort, 2000, p. 210 y CABrera, Mercedes, Juan March (1880-1962), Madrid, Marcial Pons, Ediciones de Historia, 2011, pp. 51-55. 
embarque hacia Argel ${ }^{62}$. Su hijo, Antoni Maria Ques Ventayol residió durante mucho tiempo en Orán gestionando los intereses de Joan March, de manera que la familia Ques consiguió acumular un importante patrimonio inmobiliario en Argelia ${ }^{63}$. Por otra parte, en 1915 Antoni Maria Ques, José Jorró y Joan March fueron acusados de tráfico de armas hacia los independentistas del Rif, empresa en la que se había iniciado March en 1905 asociado con los Jorró de Orán ${ }^{64}$.

La red de contrabando urdida por estos poco escrupulosos comerciantes inundó de tabaco de contrabando no sólo las islas Baleares sino buena parte de las provincias españolas del Mediterráneo y contó con una amplia nómina de colaboradores. Sin embargo, con el tiempo, algunos se opusieron al liderazgo de March. A raíz del asesinato de Rafel Garau Planas, en Valencia, en septiembre de 1916, la familia Garau se convirtió en una grave preocupación para Joan March. Así, en 1918, March maniobró para que la familia Garau, residente en Argel fuera acusada de espionaje a favor de las potencias centrales ${ }^{65}$.

Aunque fueron finalmente absueltos, las cosas volvieron a complicarse para la familia Garau en junio de 1933. Dos hombres de Joan March, Jaume Ramis, que era un conocido comerciante contrabandista y además el alcalde de Alcúdia, y su socio Bernat Sureda, se presentaron en Argel para tratar de negocios con Francesc Garau. La reunión degeneró y Garau asesinó a Ramis y Sureda en el que será conocido como el doble crimen de Argel ${ }^{66}$.

\section{Exiliados y emigrantes económicos durante la Guerra Civil de 1936-1939 y la postguerra}

El inicio de la Guerra Civil perturbó gravemente las relaciones humanas y económicas entre las islas Baleares y Argelia. Sin embargo, las comunicaciones marítimas entre Palma y Argel se restablecieron y ya volvían a funcionar como mínimo en diciembre de $1936^{67}$. En cuanto a la isla de Menorca, que permaneció fiel a la República hasta febrero de 1939, la compañía Air France estableció

62. MONJO ESTELRICH, Miquel, "March-Ques: Història d'una atracció fatal", Perifèria. Revista de Cultura, $\mathrm{n}^{\circ} 1$ (marzo 2006), pp. 4-7.

63. FeRrer guASP, Pere, Contraban, República i guerra, Palma, Edicions Documenta Balear, 2008, p. 213.

64. MONJO ESTELRICH, Miquel, "March-Ques...", p. 5.

65. FERRER GUASP, Pere, Joan March..., pp. 245-248.

66. FUllana MARTORELl, Jeroni F., Crímenes y criminales en las isla de la calma (Mallorca 1884-1951), Palma, Lleonard Muntaner, Editor, 2006, pp. 50-58, y FERRER GUASP, Pere, Contraban, República..., pp. 215-217.

67. Como lo atestigua el pasaporte de María Magraner Mayol. Consulado general de España en Argel. Pasaporte 329, expedido el 9-III-1935. Archivo particular de Cristòfol Seguí Colom (Palma). 
una línea de hidroaviones entre Marsella y Argel con escala en la bahía de Fornells a partir de mayo de $1937^{68}$. Por cierto que las autoridades republicanas de Menorca enviaron dos agentes a Francia para garantizar el abastecimiento de la isla, Enric Limosner i Pere Taltavull, que se movían entre Marsella y Argel ${ }^{69}$.

Por otra parte, la Guerra Civil y la inmediata postguerra hicieron de Argelia un destino predilecto para todos aquellos baleares que escapaban del régimen de Franco o que querían mejorar su suerte económica ${ }^{70}$.

Justo después de iniciarse la guerra, ya hubo algún mallorquín, vinculado al contrabando, que consiguió refugiarse en Argel. En Ibiza y Formentera, en septiembre de 1936, ante la inminencia de la ocupación franquista, algunas pequeñas embarcaciones se escaparon hacia Valencia y Argel. La dura represión motivó más fugas, como la de una embarcación de Formentera que llegó a Orán en febrero de $1937^{71}$. En cuanto a Menorca, en febrero de 1939, poco antes de la rendición de la isla, un velero, el < Carmen Picó>, consiguió llegar a Argel con 39 civiles, 28 militares y 10 tripulantes. Aunque las autoridades francesas les obligaron a pasar a la Francia metropolitana, algunos se escaparon y volvieron a Argelia donde podían contar con el apoyo de la comunidad de los descendientes de los emigrantes menorquines ${ }^{72}$.

Acabada la guerra, también se exiliaron en Argel algunos isleños que, encontrándose en la zona republicana, habían conseguido pasar los Pirineos a raíz de la caída de Cataluña ${ }^{73}$ o formaban parte de la flota republicana ${ }^{74}$.

Ya en la postguerra pasaron a Argel clandestinamente desde Mallorca algunos izquierdistas que seguían escondidos, otros que habían salido de la prisión pero temían más represalias y algunos que, sin ser directamente perseguidos,

68. Oliver trobat, Miquel F., L'aeroport de Palma de Mallorca: ahir i avui, Palma, Aena, 1997, p. 27.

69. MURILlO TUdURí, Andreu, "Els menorquins en el primer terç del segle XX", SERRA BUSQUETS, Sebastià (ed.), El segle XX a les Illes Balears: estudis i cronologia, Palma, Edicions Cort, 2000, p. 120.

70. MARIMON, Antoni y SANTANA, Manel, Els exiliats. Refugiats i exiliats de les Illes Balears a causa de la Guerra Civil del 1936-1939 i de la immediata postguerra, Palma, Hiperdimensional, 2006, pp. 97-114.

71. PARRON, Artur, La Guerra Civil a Eivissa i Formentera, Palma, Edicions Documenta Balear, 2000 , pp. 32 y 47.

72. JORDI, Jean Jacques, "La migración menorquina al final de la Guerra Civil, segons el fons de l'Arxiu d'Ultramar d'Aix en Provence i de l'Arxiu Departamental de Marsella", Revista de Menorca (1996, Primer Trimestre), pp. 120-144.

73. ADROVER, Aina y CABOT, Joan, Felanitx 1931-1939. República, guerra i repressió, Sant Jordi de ses Salines (Ibiza), Res Publica Edicions, 2002, pp. 92 y 130.

74. LLUY, Xico, Eivissencs i formenterers als camps nazis, Ibiza, Institut d'Estudis Eivissencs, p. 27. 
se sentían en un ambiente hostil y querían mejorar su fortuna. Un caso aparte es el secuestro, por parte de cuatro republicanos armados, en Ibiza, de la embarcación Santa Eulalia que realizaba el abastecimiento del faro de la isla de Tagomago, en octubre de 1939. Los fugitivos, todos ellos ibicencos, obligaron a la tripulación a dirigirse a Argel y acabaron en manos de la policía francesa ${ }^{75}$. En 1948, a raíz de la desarticulación de la oposición antifranquista ${ }^{76}$, se produjo una pequeña oleada de refugiados que temían ser nuevamente encarcelados en las prisiones franquistas. Uno de ellos, Francesc Pichaco Hernández, afirmaba que en Argel había treinta o cuarenta refugiados políticos mallorquines ${ }^{77}$. Todavía en 1952, un informe de la policía destacaba el activismo antifranquista, en concreto comunista, de algunos isleños que desde Argel enviaban propaganda a España a través de algunos patrones de barca ${ }^{78}$.

Además, en esos mismos años, también se produjo cierta emigración puramente económica, aunque igualmente clandestina, a causa del mayor desarrollo económico de $\mathrm{Argel}^{79}$. En septiembre de 1949, la policía desarticuló una banda que se dedicaba a trasladar mallorquines a Argel con el señuelo de una vida mejor ${ }^{80}$.

Muchos de los que escaparon de Mallorca hacia Argel en esos años lo hicieron mediante la red de embarcaciones que se dedicaban al contrabando, si bien después de la Segunda Guerra Mundial el epicentro del contrabando mallorquín se trasladó a Gibraltar y Tánger ${ }^{81}$.

Las relaciones por mar entre Palma y Argel se interrumpieron totalmente a causa de la Segunda Guerra Mundial y sólo se normalizaron a finales de los años cuarenta. En 1949, de todas maneras, sólo llegaron de Argel 86 personas, de las cuáles 50 tenían nacionalidad francesa, 33 española, 2 norteamericana y una suiza. En cuanto a las salidas, partieron vía marítima hacia la capital norteafricana 49 personas, entre las que predominaban los franceses (27) y los españoles (20), con una presencia mínima de belgas y norteamericanos ${ }^{82}$.

75. PÉREZ de ARÉVAlo LóPeZ, Francisco Javier, Los faros de las islas Baleares ante los conflictos bélicos contemporáneos (1847-1945), Palma, Universitat de les Illes Balears, tesis doctoral inédita, 2012, pp. 499-502.

76. GINARD, David, La resistència antifranquista a Mallorca (1939-1948), Palma, Edicions Documenta Balear, 1991.

77. GINARD, David, Treballadors, sindicalistes i clandestins. Històries orals del moviment obrer a les Balears (1930-1950), Palma, Edicions Documenta Balear, 2012, vol. I, p. 197.

78. GINARD, David, L'exili balear del 1939, Palma, Edicions Documenta Balear, 2008, p. 61.

79. Algunos casos pueden encontrarse en FERRÀ-PONS, Damià, Gent de Campanet. Veus d'un món perdut, Palma, Ajuntament de Campanet, 2003, pp. 258-279.

80. SERRA BUSQUETS, Sebastià (ed.), El segle XX..., p. 498.

81. FERRER GUASP, Pere, Contraban, república..., pp. 89-101.

82. Arxiu Històric del Regne de Mallorca, Estadística, Caja 350, Movimiento de Buques y Pasajeros 1941-1950. 
En diciembre de 1949, un barco de la Cie. De Navigation Mixte de Marseille unía semanalmente Palma con Marsella y Argel de manera que el tránsito se incrementó en los años cincuenta. Además, la compañía de aviación Air Algerie volaba dos veces por semana de Palma a Argel y viceversa mientras que las Líneas Aéreas del Mediterráneo disponían de un vuelo semanal de ida y otro de vuelta entre estas dos ciudades ${ }^{83}$. En esa época las únicas ciudades extranjeras a las que se podía volar desde Palma eran Argel, Marsella y Génova, aunque esta situación pronto se transformaría radicalmente.

\section{El final de la Argelia francesa. Refugiados políticos y pied-noirs}

A principios de los años cincuenta residían en la próspera y todavía pacífica Argelia los descendientes de la gran emigración menorquina de 1830-1845, muchos de los cuales mantenían todavía las costumbres e incluso el idioma de su isla de origen ${ }^{84}$, así como los emigrantes económicos de todas las islas de finales del siglo XIX y principios del siglo XX, a los que se habían unido más recientemente los exiliados de la Guerra Civil y del primer franquismo y los nuevos emigrantes económicos provocados por las penurias y los problemas socioeconómicos de la España autárquica. Significativamente, la asociación Les Cadets de Majorque, creada en 1953 para aglutinar a los mallorquines (y a los otros baleares) en Francia, entre 1954 y 1962 tuvo 53 socios en Argelia, que suponían el 6,5\% del total. Estos socios se concentraban en Argel (28) y Fort de l'Eau (21), si bien también había dos asociados en Bab el Oued y otros dos en Ouled-Fayed. En la mayoría de los casos se trataba de socios individuales, pero también había dos empresas radicadas en Argel, Colom et ses Gendres y Borrás et Sampol ${ }^{85}$.

La larga Guerra de Argelia (1954-1962) modificó completamente la vida de todos los europeos residentes en la colonia francesa ${ }^{86}$. Algunos colonos descendientes de las islas Baleares pronto abandonaron la colonia, pero otros lo hicieron en el último momento. Por otra parte, si bien la mayoría no quería intervenir en cuestiones políticas, podemos documentar algún caso de incor-

83. muntaner bujosa, Juan, Guía oficial de la Ciudad de Palma de Mallorca, Palma, Comisión Municipal de Turismo, 1949, pp. 233 y 235.

84. MARFANY, Marta, Els menorquins..., pp. 43-64.

85. GarCía montserRat, Ana Laura, "Paris Baleares", l'òrgan de difusió de l'associació Les Cadets de Majorque (1954-1965), Palma, Universitat de les Illes Balears, memoria de investigación inédita, 2006, pp. 242-244, 250 y 259.

86. Sobre la guerra de Argelia pueden consultarse STORA, Benjamin y HARBI, Mohammed, La Guerre d'Algérie 1954-2004. La fin de l'amesie, Paris, Hachette, 2004; BRANCHE, Raphaële, La Guerra d'Algérie, une histoire apaisée?, Paris, Seuil, 2005 y MIQuel, Pierre, La Guerre d'Algérie, Paris, Fayard, 1993. 
poración a la OAS, el grupo armado que defendió a ultranza la existencia de una Argelia francesa ${ }^{87}$. Un ejemplo extremo es el de Lluís García Barranco (Esporles 1926 - Campanet 1991), que había llegado a Argel en 1949 procedente de Francia. Hacia 1961 se incorporó a la Organisation Armée Secrète-OASy participó en diversos atentados hasta que, al final de la guerra, pasó a Alicante y durante cierto tiempo continuó cobrando una paga mensual de la organización armada ${ }^{88}$. Por otra parte, como mínimo un ibicenco murió víctima del terrorismo argelino. Se trata de Joan Torres Torres, que falleció a causa de un atentado en Argel en febrero de $1962^{89}$.

Como es lógico, la guerra afectó directamente a los jóvenes descendientes de las islas Baleares que tenían la nacionalidad francesa, tanto si residían en Francia como en Argelia. Conocemos las vicisitudes en el ejército francés de Cristòfol Seguí Colom, hijo de una familia de comerciantes mallorquines establecidos en Argel $^{90}$ y también podemos documentar el caso de Jean Mendiola, hijo de unos comerciantes mallorquines establecidos en París, que murió en combate en tierras argelinas el 10 de mayo de $1957^{91}$.

Probablemente por motivos de proximidad y por cierta afinidad ideológica con el régimen de Franco, algunos franceses de Argelia sin ningún vínculo familiar con las islas Baleares se refugiaron en este archipiélago a causa de la retirada francesa de Argelia. En ciertos casos no hay duda sobre su rechazo a la política del presidente Charles de Gaulle y, a partir de febrero de 1961, es probable su vinculación a la OAS. Así, en marzo de 1960, llegó a Palma Jacques André Georges Laquiere, abogado con domicilio en Argel, que se presentó en la comisaría de policía de Palma y solicitó "ser considerado como refugiado político y acogerse a la protección del pabellón español”92.

Otros franceses de Argelia refugiados vigilados por la policía de Palma fueron el señor Ourval, que en mayo de 1961 recibió procedente de Argel su tía, Matilde Raoux, y su madre política, France Koller; así como Pierre Joly y JeanJacques Susini, que en diciembre de 1960 embarcaron hacia Barcelona acom-

87. Sobre la OAS son imprescindibles los estudios de HARRISOn, Alexander, Le défi a De Gaulle. L'OAS et la contra-revolution en Algérie 1954-1962, Paris, L'Harmattan, 2008 y KAUFFER, Rémi, OAS: Histoire d’une guerre franco-française, Paris, Seuil, 2002.

88. FERRÀ-PONS, Damià, Gent de Campanet..., pp. 250-257.

89. Arxiu del Regne de Mallorca, Gobierno Civil, Caja 816, Extranjeros 1960-1963.

90. MARIMON RIUTORT, Antoni, D'Alger a sa Granja d'Esporles..., pp. 37-48.

91. Paris-Baleares, París, $\mathrm{n}^{\circ}$ 39, junio de 1957.

92. Arxiu del Regne de Mallorca, Gobierno Civil, Caja 816, Extranjeros 1960-1963, sobre refugiados argelinos en Mallorca. Carta reservada del Gobernador Civil de Baleares al ministro de la Gobernación, 15-III-1960. 
pañados de un funcionario de la Brigada de Investigación Social de Madrid ${ }^{93}$. Poco después, en febrero de 1961, en Madrid, Jean-Jacques Susini fue uno de los fundadores de la OAS. En diciembre de 1963, la Guardia Civil de Inca (Mallorca) detuvo al francés de Argelia Jean Alain de Corti, que residía en Alcúdia, a demanda del Juzgado de Instrucción número 2 de Almería ${ }^{94}$.

Por otra parte, en esos años eran frecuentes las demandas de información del Consulado de Francia en las Baleares al Gobernador Civil sobre ciudadanos franceses, aunque no se especifica el motivo ${ }^{95}$.

En la primera mitad de los años sesenta residía en Mallorca una colonia de pied-noirs, es decir de antiguos habitantes europeos de Argelia. Muchos de ellos sólo estaban de paso en la isla y esperaban que surgiese alguna oportunidad para poderse instalar en países como Argentina o Australia. Otros, intentaban aprovechar el enorme crecimiento turístico de Mallorca para hacer sus negocios. Evidentemente, los más comprometidos con la OAS no podían dirigirse a Francia ${ }^{96}$.

El final de la Argelia francesa hizo que la práctica totalidad de los emigrantes baleares y sus descendientes tuvieran que abandonar el norte de África. La mayoría de menorquines nacidos en Argelia, ya muy afrancesados, pasaron casi todos a la Francia metropolitana ${ }^{97}$. Los emigrantes económicos de Mallorca, en general, regresaron a la isla en la que tenían parientes y amigos ${ }^{98}$. En cuanto a los exiliados políticos, algunos no querían regresar a la España de Franco y pasaron a Francia, como fue el caso del exdirigente de las Juventudes Socialistas Unificadas Jaume Serra Obrador y su esposa Magdalena Nebot ${ }^{99}$. Pero otros, como Gabriel Gomila y su familia, se instalaron en Llucmajor ${ }^{100}$ en la isla de Mallorca. Todavía en diciembre de 1963, la Guardia Civil vigilaba discretamente a Josep Nadal Nicolau, avecindado en Hussein Dey y con pasaporte expedido en Argel, que regresó a Alaior (Menorca) para pasar las navidades con sus familiares ${ }^{101}$.

93. Ibid., Telefonema 550, 14-XII-1960.

94. Ibid., Dirección General de Seguridad, Delegación Especial de Baleares, Comisaría de Palma, 18-XII-1963.

95. Ibid., por ejemplo el 03-V-1963 con respuesta del Gobierno Civil de Baleares del 11V-1963.

96. MARIMON RIUTORT, Antoni, D'Alger a sa Granja d'Esporles..., pp. 55-56.

97. MARFANY, Marta, Els menorquins..., p. 68.

98. Por ejemplo, la familia Seguí Colom, MARIMOn RIUTORT, Antoni, D’Alger a sa Granja d'Esporles..., pp. 48, 49.

99. GINARD, David, L'exili balear..., p. 52.

100. MARFANY, Marta, Els menorquins..., p. 68.

101. Arxiu del Regne de Mallorca, Gobierno Civil, Caja 816, Extranjeros 1960-1963, Nota informativa confidencial Servicio de Información, 17-XII-1963. 


\section{Algunas conclusiones}

Con el final de la Argelia francesa, en 1962, las islas Baleares perdían un referente económico, social y cultural. El éxodo de los pieds-noirs y la creación de una República árabe y musulmana supusieron una ruptura casi total de las relaciones entre el archipiélago balear y Argelia. De repente, parecía que la distancia se había multiplicado y las complicidades de todo tipo tejidas entre ambos territorios se desvanecieron casi del todo. Durante los ciento treinta y dos años de colonización francesa, Argelia se convirtió inicialmente para las islas Baleares en el destino de una sorprendente emigración masiva de carácter campesino, los llamados "mahoneses" (menorquines), que casi hasta el final mantuvieron su identidad diferenciada.

Posteriormente, una minoría de comerciantes se instaló en la colonia y se fueron desarrollando unos interesantes vínculos económicos, tanto en el ámbito legal como en el ilegal. Aunque no puede cuantificarse, el contrabando de tabaco adquirió proporciones masivas en el primer tercio del siglo XX. Paralelamente, y en parte gracias a la mejora de las comunicaciones, desde todas las islas se dirigió a la Argelia francesa una emigración temporal que trabajaba principalmente en la siega y la vendimia.

La Guerra Civil y la Segunda Guerra Mundial, como es lógico, dificultaron las relaciones entre las islas Baleares y la colonia francesa, pero numerosos exiliados republicanos alcanzaron sus costas y no faltaron tampoco los emigrantes económicos clandestinos. Sin duda la proximidad geográfica se conjugaba con el atractivo de unas mejores expectativas económicas y con la constatación que no era muy difícil integrarse en la entonces próspera comunidad europea de Argelia.

Por otra parte, tampoco puede olvidarse el papel jugado por las islas Baleares como puente entre la Francia metropolitana y Argelia. En conjunto, aunque la emigración y las relaciones económicas con Francia y Latinoamérica ciertamente fueron muy importantes, el papel jugado por la Argelia francesa fue mucho más relevante de lo que se deduce en la cada vez más abundante bibliografía sobre las islas Baleares en los siglos XIX y XX.

El final de la Argelia francesa hizo que una frontera permeable y accesible se convirtiese en un muro invisible pero de hecho casi infranqueable. Más de un siglo de intensas relaciones fueron desapareciendo incluso de la memoria histórica.

102. Població estrangera resident a les Illes Balears. Característiques demogràfiques 1962-1991, Palma, Govern de les Illes Balears, Conselleria d'Economia, Comerç i Indústria, 2002, p. 39. 
Las relaciones económicas se redujeron hasta casi desaparecer mientras que en el ámbito migratorio sólo puede señalarse una emigración argelina, tanto legal como ilegal, a partir de los años noventa del siglo XX. Con todo, todavía en 1997 no había ni 200 residente argelinos en las islas Baleares ${ }^{102}$. El año 2001 , los residentes permanentes ya eran 658 y los temporales 2.415 , pero en un contexto de extraordinario auge de la inmigración se trataba de cifras modestas muy inferiores a la emigración marroquí y poco acordes con la proximidad geográfica de Argelia ${ }^{103}$.

En definitiva, la Argelia francesa constituyó un importante foco de atracción, tanto para la emigración como para algunos sectores económicos de las islas Baleares. Sin embargo, estas relaciones casi no han tenido continuidad con la República Argelina Democrática y Popular creada en 1962.

103. SALVÀ tOMÀs, Pere A., "Les Illes Balears: un espai de cruilla de fluxos migratoris", Llengua i ús, $\mathrm{n}^{\circ} 24$ (segundo cuatrimestre 2002), pp. 4-11. 